\title{
Three different DnaK proteins are functionally expressed in the cyanobacterium Synechocystis sp. PCC 6803
}

\author{
Correspondence \\ Dirk Schneider \\ Dirk.Schneider@biochemie. \\ uni-freiburg.de
}

Received 9 January 2007

Revised 6 February 2007

Accepted 7 February 2007

\author{
Eva Rupprecht, ${ }^{1,2}$ Sven Gathmann, ${ }^{1,2}$ Eva Fuhrmann ${ }^{1,2}$ \\ and Dirk Schneider ${ }^{1}$
}

\author{
${ }^{1}$ Institut für Biochemie und Molekularbiologie, Zentrum für Biochemie und Molekulare \\ Zellforschung, Albert-Ludwigs-Universität Freiburg, Stefan-Meier-Strasse 19, 79104 Freiburg, \\ Germany \\ ${ }^{2}$ Fakultät für Biologie, Albert-Ludwigs-Universität, 79104 Freiburg, Germany
}

\begin{abstract}
Multiple dnaK genes appear to be common in cyanobacteria; the function of the encoded proteins is, however, still elusive. To characterize the dnaK gene family from the cyanobacterium Synechocystis sp. PCC 6803 in detail, genetic analyses were combined with analyses of the expression and localization patterns of the three encoded proteins. While significant expression of all three genes was found, the results obtained clearly indicate physiological differences of the three proteins in vivo, and DnaK2 seems to have a key function in Synechocystis. Expression of DnaK3 appears also to be as essential as expression of DnaK2, whereas the dnaK1 gene was deleted without resulting in any distorted phenotype. In line with a suggested privileged function, expression of DnaK2 altered most significantly after heat shock.
\end{abstract}

\section{INTRODUCTION}

Proteins of the $70 \mathrm{kDa}$ heat-shock protein family (Hsp70) are ubiquitously distributed in all kingdoms of life, and in eukaryotes members of this family can be found in several organelles as well as in the cytosol (Bukau \& Horwich, 1998; Bukau et al., 2006). The main functions of the proteins are to ensure proper folding of polypeptide chains, to keep proteins in a translocation-competent state after synthesis, and to prevent misfolding and aggregation of proteins caused by e.g. cellular stress. Although some Hsp70 proteins are involved in the cellular heat-shock response, the proteins are usually constitutively expressed and functional, and therefore members of the Hsp70 family are better described as chaperones rather than as heatshock proteins (Rospert \& Chacinska, 2006).

Besides the structure of an almost complete bovine Hsc70 protein (Jiang et al., 2005), the structure of the $\sim 45 \mathrm{kDa} \mathrm{N}$ terminal ATPase domain has been resolved recently (Flaherty et al., 1990; Harrison et al., 1997; Zhang \& Zuiderweg, 2004) as well as the structure of the $25 \mathrm{kDa}$ peptide-binding domain (Cupp-Vickery et al., 2004; Wang et al., 1998; Zhu et al., 1996), which is linked to the ATPase domain via a short flexible linker. The C-terminal part of Hsp70 proteins is not well conserved, and the physiological function of this domain is less characterized.

In recent years, the Hsp70 protein from Escherichia coli (DnaK) has become a paradigm for studying the activity and function of Hsp70s, and the general mechanism of
DnaK activity has been mainly investigated in E. coli. Interestingly, the dnaK gene can be easily deleted in E. coli, although the deletion strain displayed defects in cell growth at low and high temperatures (Bukau \& Walker, 1989a, b; Paek \& Walker, 1987). The ATPase activity of E. coli DnaK is regulated by the two co-chaperones DnaJ and GrpE. DnaJ enhances the substrate-binding activity of Hsp70 by stimulating its ATPase activity, and GrpE is a nucleotide exchange factor. When ATP is bound to the ATPase domain of Hsp70s the protein possesses weak chaperone activity, whereas when ADP is bound the protein binds tightly to substrates (Harrison, 2003; Liberek et al., 1991).

While in eukaryotes several different Hsp70 proteins exist in the various cellular compartments, in bacteria usually only a single DnaK protein is present. Nevertheless, in a few bacteria more than one DnaK homologous protein exists, and in E. coli, for example, two DnaK-homologous proteins can be found besides the canonical DnaK (Lelivelt \& Kawula, 1995; Seaton \& Vickery, 1994; Yoshimune et al., 1998). While this is rather uncommon in other bacteria, all cyanobacteria appear to encode several DnaK proteins as deduced from the available genomic sequence information. A dnaK multigene family was originally identified in the cyanobacterium Synechococcus sp. PCC 7942 (Nimura et al., 1994a, b, 1996, 2001), but later on it became evident that also in the genomes of other completely sequenced cyanobacteria dnaK gene families exist, the functions of which are still largely unknown. As in Synechococcus, in the genome of the mesophilic 
cyanobacterium Synechocystis sp. PCC 6803 three dnaK genes can be found, which encode highly homologous proteins (Kaneko et al., 1996). In contrast to Synechococcus, it has recently been proposed that only one $d n a K$ gene is functionally expressed in Synechocystis whereas the other two genes are silent (Varvasovszki et al., 2003).

Here we present an analysis of the expression and function of the three DnaK proteins in Synechocystis, and the results contrast with some observations made in Synechococcus. Since Synechocystis can grow under various experimental conditions and can be easily genetically modified, it appears to be an excellent model organism to study the functions of a cyanobacterial DnaK family. Based on immunological analysis we found that all three DnaK proteins are expressed in Synechocystis, although deletion analyses indicated that the function of DnaK2 and DnaK3 is physiologically of greater importance than the function of DnaK1. Furthermore, only for the dnaK2 gene expression did we observe a heat-stress response typical for heat-shock protein genes.

\section{METHODS}

Cell culture. A glucose-tolerant Synechocystis sp. PCC 6803 wild-type strain (kind gift of M. Rögner, Bochum, Germany) was maintained in liquid BG11 medium (Rippka et al., 1979) at $34{ }^{\circ} \mathrm{C}$ under $33 \mu \mathrm{E} \mathrm{m}{ }^{-2}$ $\mathrm{s}^{-1}$ of fluorescent cold white light. For cultivation of mutant strains, $30 \mu \mathrm{g}$ kanamycin $\mathrm{ml}^{-1}$ was added to the medium. All cultures were grown photoautotrophically unless otherwise indicated. E. coli strain $\mathrm{DH} 5 \alpha$ was used for plasmid propagation. Temperature-sensitive $E$. coli strains $\Delta d n a K 52$ and $\Delta d n a K 756$ were maintained at $30{ }^{\circ} \mathrm{C}$.

Preparation of cellular protein fractions. Synechocystis cells were harvested at exponential growth phase $\left(\mathrm{OD}_{750} 0.5-2.0\right)$. Pelleted cells were resuspended in $50 \mathrm{mM}$ HEPES $\mathrm{pH} 8.0$ and broken with glass beads $(0.25-0.5 \mathrm{~mm}$ diameter $)$ in a Mini Beadbeater. To prevent protein degradation a proteinase inhibitor mix was added to the cell suspension. Glass beads and unbroken cells were removed by centrifuging twice at $1600 \mathrm{~g}$. Soluble and membrane protein fractions were obtained by ultracentrifugation of the total cell extract at $48000 \mathrm{~g}$ for $30 \mathrm{~min}$. Pelleted membranes were washed with HEPES buffer and resuspended in the same volume as the supernatant.

Alkali extraction of membrane proteins. A Synechocystis wild-type cell culture grown in the presence of $5 \mathrm{mM}$ glucose was harvested at exponential growth phase $\left(\mathrm{OD}_{750} \approx 1\right)$. The pellet was resuspended in $50 \mathrm{mM}$ HEPES/KOH $\mathrm{pH} 8.0$ and total cell extract was prepared as described above. The extract was divided into $1000 \mu \mathrm{l}$ samples and membranes were sedimented by ultracentrifugation. The supernatant was discarded and the pelleted membranes were washed and then resuspended in $500 \mu \mathrm{l}$ HEPES buffer (control) or in $500 \mu$ l of the same buffer containing either $100 \mathrm{mM} \mathrm{NaOH}$ or $100 \mathrm{mM} \mathrm{Na}_{2} \mathrm{CO}_{3}$. After incubation for $30 \mathrm{~min}$ on ice, membranes were recovered by ultracentrifugation. The supernatant was collected and the membranes were resuspended in the same volume of HEPES buffer. Equal volumes of soluble and corresponding membrane protein sample were subjected to SDS-PAGE and Western analysis.

Electrophoresis and Western blotting analysis. Proteins were separated by SDS-PAGE using $8 \%$ polyacrylamide gels according to standard procedures (Sambrook et al., 1989). For Western analysis, proteins were transferred onto PVDF membranes. The individual
DnaK proteins were detected with primary antibodies, raised in rabbits (see Fig. 1 for the peptide sequences used), and an anti-rabbit IgG alkaline-phosphatase-conjugated secondary antibody.

Disruption of dnaK genes. All molecular methods were done by standard procedures (Sambrook et al., 1989).

To disrupt the individual $d n a K$ genes, the individual genomic regions were amplified by PCR using the following primers: NtdnaK1 $\left(5^{\prime}\right.$-atagccatatgggcaaagtcattggcattg- $\left.3^{\prime}\right), \quad$ CtdnaK1 $\quad\left(5^{\prime}\right.$-tatcgggatccctaatcgatcgcttcatagtcac- $\left.3^{\prime}\right), \quad \mathrm{NtdnaK} 2 \quad\left(5^{\prime}\right.$-tatgccatatgggaaaagttgttgggattg- $\left.3^{\prime}\right)$, CtdnaK2 (5'-atacgggatccctatttctccggctcagag- $\left.3^{\prime}\right)$, NtdnaK3 ( $5^{\prime}$-attgccatatgggaaaagtcgtcggaattg- $\left.3^{\prime}\right)$, CtdnaK3 (5' -tagcaagcttttaatgatgatggtgatgatggtgat $\left.-3^{\prime}\right)$. The isolated fragments were ligated into the restriction-digested plasmid pRSET6a (Schoepfer, 1993), and a kanamycin resistance cassette $(a p h A)$, derived from the plasmid pBSL14 (Alexeyev, 1995), was inserted into the genes via SmaI (dnaK1 and dnaK2) or HincII (dnaK3) restriction sites. The constructs were transformed into Synechocystis wild-type cells (Williams, 1988) and positive clones were selected on BG11 agar plates containing $10 \mu \mathrm{g}$ kanamycin $\mathrm{ml}^{-1}$. Positive clones were continuously transferred onto selective agar plates containing increasing concentrations of kanamycin (up to $100 \mu \mathrm{g} \mathrm{ml}^{-1}$ ) for more than a year. To check whether the deletion strains were completely segregated, genomic DNA was isolated and the corresponding regions were analysed by PCR and restriction analysis. For the isolation of the dnaK genomic regions the following primers were used: NtdnaK1, CtdnaK1, NtdnaK2, CtdnaK2, NtdnaK3check (5'-gtttttagaagcggagaaagtgg- $\left.3^{\prime}\right)$ and CtdnaK3check ( $5^{\prime}$-cctttgggttggaaaccattgg- $\left.3^{\prime}\right)$.

\section{Heterologous expression of Synechocystis DnaK proteins in E.} coli. The individual $d n a K$ genes were amplified by PCR using the primers NtdnaK1, CtdnaK1HindIII (5'-tatcgaagcttctaatcgatcgcttcatagtcac-3'), NtdnaK2, CtdnaK2, NtdnaK3 and CtdnaK3. The isolated fragments were ligated into a modified version of the pBAD24 expression vector (Guzman et al., 1995) via the NdeI/HindIII restriction sites (dnaK1 and dnaK3) or via NdeI/BamHI (dnaK2). For protein expression, these constructs were transformed into E. coli $\Delta$ dnaK52 (Bukau \& Walker, 1989b). Cultures were grown at $30{ }^{\circ} \mathrm{C}$ and DnaK protein expression was induced at an $\mathrm{OD}_{600}$ of 0.6 with $0.2 \%$ arabinose. After $6 \mathrm{~h}$ cells were harvested and broken by sonication. Unbroken cells were removed from the extracts by centrifugation at $1600 \mathrm{~g}$.

Generation of dnaK reporter strains. The promoter regions of each $d n a K$ gene were amplified by PCR and introduced upstream of the $\operatorname{lu} x A B$ reporter genes on the promoter-probe vector pILA (Kunert et al., 2000) via the PstI/KpnI restriction sites. The constructs were transformed into Synechocystis wild-type cells, and positive clones were selected and further treated as described above. For calculation of background luminescence a control strain (luxAB without any promoter fused) was also generated.

Luminescence measurement of dnaK promoter activity. Measurement of $d n a K$ promoter activities was performed using a Lumat LB 9507 luminometer (Berthold Technologies). Synechocystis cells were diluted in fresh BG11 medium to an $\mathrm{OD}_{750}$ of 0.5 . Luciferase reactions of $1 \mathrm{ml}$ cell suspensions were measured after addition of $1 \mathrm{mM}$ decanal (50 mM stock solution in $100 \%$ ethanol), and luminescence was measured for $30 \mathrm{~s}$.

Complementation of an E. coli TS $\Delta$ dnaK strain. The E. coli dnaK gene was amplified using the primers NtdnaKEC ( $5^{\prime}$ ctactcatatgggtaaaataattggtatcg- $\left.3^{\prime}\right)$ and CtdnaKEC (5'-ggccgaagcttcaccggcagtctgctgc- $\left.3^{\prime}\right)$, and genomic E. coli DNA as template. The genes encoding the E. coli DnaK protein and Synechocystis DnaK proteins (see above) were cloned into the pMal-c2 (New England 
MGKI I GIDLGTTNSCVAIMDGTTPRVLENAEGDRTTPSI IAYTQDGETLVGQPAKRQAVT MGKVIGIDLGTTNSCASVLEGGKPIVITNTEGGRT'TPS IVGETKGSQRLVGQLAKRQSVT MGKVVGIDLGTTNSCVAVMEGGKPTVIANAEGFRTTPSVVGYAKNGDRLVGQIAKRQAVM MGKVVGIDLGTTNSVVAVMEGGKP IVIANAEGMRTTPSVVGFNKEGELVVGQMGRRQAVL

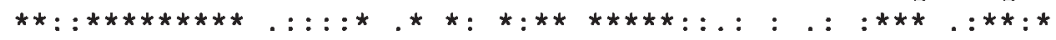

NPQNTLFAI RRLIGRRFQDEEVQRDVS IMPEKI I AADNGDAWVEVKGQ--KMAPPQI SAE NAENTVYSIKRFIGRRWDDTVEER--SRVPYNCVKGRDDTVSVSIRGQ--SYTPQEI SAM NPGNTFYSVKRFIGRKFDEITNEA--TEVAYSVVKDGNGNVKLDCPAQGKQFAPEEISAQ NPQNTFYGVKRFMGRRYTDLTPES--KRVAYTIRRDDRDNIKVRCPRLKKDFAPEEI SAM

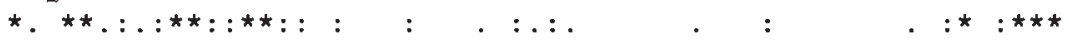

VLKKMKKTAEDYLGEPVTEAVITVPAYFNDAQRQATKDAGRIAGLEVKRI INEPTAAALA ILQKLKADSEAFLGEPVTQAVITVPAYFTDAQRQATKDAGTIAGLEVLRI INEPTAAALA VLRKLVDDASKYLGETVTQAVITVPAYENDSQROATKDAGKIAGIEVLRI INEPTAASIA ILRKLAEEASRYLGEKVTGAVITVPAYFNDSQRQATRDAGKIAGLEVLRI INEPTAASLA

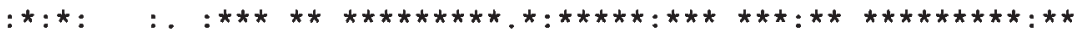

E. coli Dnak1

Dnak2

Dnak3

E. $\operatorname{Col} i$ Dnak1

Dnak2

Dnak3

E. Coli

Dnak1

Dnak2

Dnak3

E. coli

Dnak1

DnaK2

Dnak3
YGLDKGTGNRT IAVYDLGGGTFDISI IEIDEVDGEKTEEVLATNGDTHLGGEDEDSRLIN YGLDKOETEELILVFDLGGGTEDVSLLQL----GNGVEEVLSTSGNNHLGGDDFDNCVVO YGLDKKD-NETILVFDLGGGTFDVSILEV----GEGVFEVLATSGDTHLGGDDFDKKIVD YGLDQGR-IQKILVFDLGGGTFDVSVLEV----GDGI FEVKATSGDTQLGGNDFDRRIVD

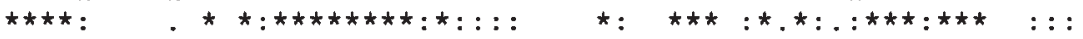

YLVEEFKKDQGIDLRNDPLAMQRLKEAAEKAKIELSSAQQTDVNLPYITADATGPKHMNI WMAES FKQKENIDLST DKMAIQRL REAAEKAKIELSSMLNTT INLPFITADESGPKHLEM FLAGEFQKAEGIDLRKDKQALQRLTEAAEKAKIELSGVSQTEINLPFITATQDGPKHLDT WLAEKFLEAEKVDLRODROALQRLTEAAEKAKIELSGVGTTEINLPFITATEDGPKHLET

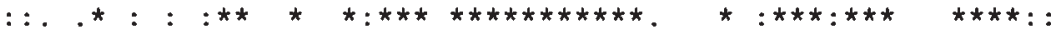

KVTRAKLESLVEDLVNRS IEPLKVALQDAGLSVSDIDDVILVGGQTRMPMVQKKVAEFFG ELARSQFEELTKQLLEDTRVPLTQALDDGEIRASDVHRVILVGGSTRI PAIQRVIQEFFP TLSRAKEEEICSDLIDRCGIPVENAIRDAKIDKSALDEIVLVGGSTRIPAVQEVVKKILG QLSRSEFEDLCGDLVTRLQRPVKRVLKDAGLSPVQIDEVVLVGGGTRMPMVKGLVRSFID

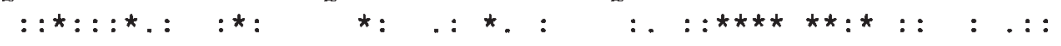

-KEPRKDVNPDEAVAIGAAVQGGVLTGDVKDVLLLDVTPLSLGIETMGGVMTTLIAKNTT -KDPNQGVNPDEVVAVGAAIQGGVLSGEVKDI LLLDVS PLSLGVETLGGVMTKI I PRNTT -REPNENVNPDEVVAIGAAIQAGILDGEVKDI LLLDVTPLSFGLETIGGVMKKLLPRNTT

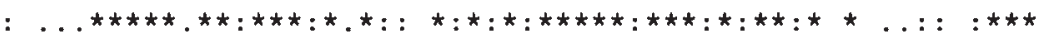
DSQLERSVNPDEAVALGAAIQAGVIGGEVEDVLLLDVTPLSLGLETLGEVTTKIIERNTT
Biolabs) expression plasmid via NdeI/HindIII restriction sites. The resulting plasmids were transformed into E. coli $\Delta d n a K 756$ (Georgopoulos et al., 1979) and cells were grown at $30{ }^{\circ} \mathrm{C}$. A $50 \mu \mathrm{l}$ culture volume of each transformant was used to inoculate cultures of $3 \mathrm{ml} \mathrm{LB}$ containing ampicillin and various concentrations of IPTG, and the cultures were subsequently incubated at either $30{ }^{\circ} \mathrm{C}$ or $42{ }^{\circ} \mathrm{C}$ overnight. Cell growth was followed by measuring the $\mathrm{OD}_{600}$. For the determination of the DnaK protein localization, cellular protein fractions were prepared from cultures grown at $30{ }^{\circ} \mathrm{C}$.

Expression of a C-terminally truncated DnaK3 version. Genes encoding the full-length DnaK3 as well as a C-terminally truncated DnaK3 version were amplified using the primers NtdnaK3SalI $\left(5^{\prime}\right.$-tatgcgtcgaccetttgtcaccagtggtttgc- $\left.3^{\prime}\right)$ and CtdnaK3SpeI (5'-atagcactagtttagaaccaatcatcatcgtcatc- $3^{\prime}$ ) or CtdnaK3shortSpeI ( $5^{\prime}$-atagcactagtttaggtgaccctggactggtcc- $\left.3^{\prime}\right)$, respectively. The resulting fragments were ligated into the plasmid pILA (Kunert et al., 2000) via the SalI/ $\mathrm{XbaI}$ restriction sites. The construct for the complete deletion of the genomic dnaK3 gene was generated as follows. The region $400 \mathrm{bp}$ upstream of the dnaK3 gene was amplified using the primers NtdnaK3SalI and CtdnaK3us ( $5^{\prime}$-ccatgttgttttctttgctcc- $\left.3^{\prime}\right)$ and ligated into the TA cloning vector pCR2.1 (Invitrogen). The $400 \mathrm{bp}$ downstream region of the dnaK3 gene was amplified using the primers NtdnaK3ds ( $5^{\prime}$-atcggttctaatgtcaaaagttcg- $\left.3^{\prime}\right)$ and CtdnaK3ds $\left(5^{\prime}\right.$-atacgctcgaggccattgacacttgttccg- $\left.3^{\prime}\right)$. The resulting fragment was ligated into the construct harbouring the upstream $d n a K 3$ region via the EcoRV/Xhol restriction sites, corresponding to a direct orientation of both dnaK3 flanking regions. A chloramphenicol resistance cassette was amplified from the plasmid pACYC184 (New England Biolabs) using the primers NtcmR (5'-cactttgcgecgaataaatacc- $\left.3^{\prime}\right)$ and CtcmR (5'-ttacgcccegccetgcc- $\left.3^{\prime}\right)$ and subsequently ligated into the EcoRV restriction site between the dnaK3 upstream and downstream regions in direct orientation. After transformation of the pILADnaK3 expression constructs and the dnaK3 deletion construct into Synechocystis wild-type cells and selection of positive clones on plates containing increasing amounts of kanamycin (see above), complete segregation of the mutant strains was investigated by PCR.

Miscellaneous techniques. Sequences of the individual cyanobacterial DnaK proteins were retrieved from the Cyanobase (http:// www.kazusa.or.jp/cyanobase/). The program CLUSTAL x (Thompson et al., 1997) was used to calculate the alignments and the phylogenetic tree. All alignment parameters remained as pre-set by the program. 


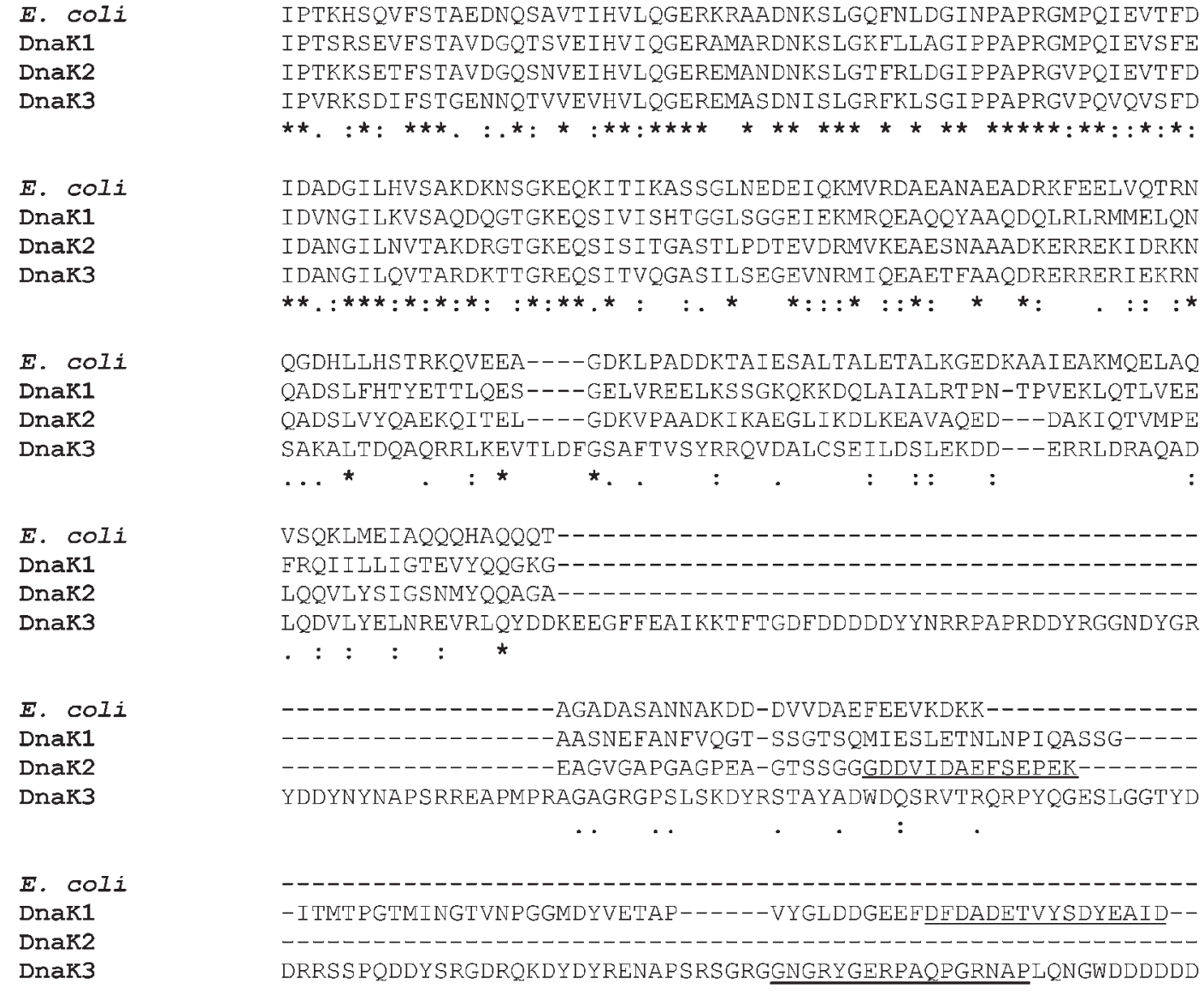

E. Coli

Dnak1

Dnak2

Dnak3

IDADGILHVSAKDKNSGKEQKITIKASSGLNEDEIQKMVRDAEANAEADRKFEELVQTRN IDVNGILKVSAQDQGTGKEQSIVISHTGGLSGGEIEKMRQEAQQYAAQDQLRLRMMELQN IDANGILNVTAKDRGTGKEQSISITGASTLPDTEVDRMVKEAESNAAADKERREKIDRKN IDANGILQVTARDKTTGREQSITVQGASILSEGEVNRMIQEAETFAAQDRERRERIEKRN

QGDHLLHSTRKQVEEA----GDKLPADDKTAIESALTALETALKGEDKAAIEARMQELAQ QADSLFHTYETTLQES----GELVREELKSSGKQKKDQLAIALRTPN-TPVEKLQTLVEE QADSLVYQAEKQITEL----GDKVPAADKIKAEGLIKDLKEAVAQED---DAKIQTVMPE SAKALTDQAQRRLKEVTLDFGSAFTVSYRRQVDALCSEILDSLEKDD---ERRLDRAQAD

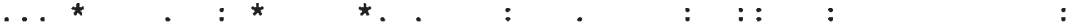

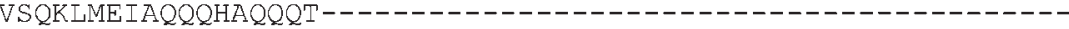

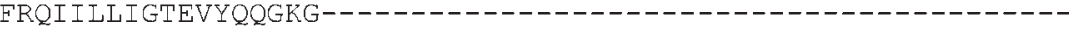
LQQVLYSIGSNMYQQAGA-. : : : : -------------- AASNEFANEVQGT-SSGTSQMIESLETNLNPIQASSG----
--------------- EAGVGAPGAGPEA-GTSSGGGDDVIDAEFSEPEK ------
YDDYNYNAPSRREAPMPRAGAGRGPSLSKDYRSTAYADWDQSRVTRQRPYQGESLGGTYD -ITNTPGTMINGTVNPGGMDYVETAP------VYGLDDGEEEDEDADETVYSDYEAID-DRRSS PQDDYSRGDRQKDYDYRENAPSRSGRGGNGRYGERPAQPGRNAPLQNGWDDDDDD

Fig. 1. Sequence alignment of the three DnaK proteins from Synechocystis PCC 6803 and from E. coli. Peptide sequences that were used for raising antibodies against the individual Synechocystis DnaK proteins are underlined.

\section{RESULTS}

\section{Three DnaK proteins in Synechocystis}

In the genome of the cyanobacterium Synechocystis sp. PCC 6803 three genes code for potential DnaK proteins (Kaneko et al., 1996) (Fig. 1). The encoded DnaK proteins share a high degree of sequence homology to each other as well as to DnaK proteins from other species. The dnaK2 gene encodes a protein with a calculated molecular mass of 67 $\mathrm{kDa}$ and this protein shows the highest sequence identity to the E. coli DnaK protein as well as to chloroplast Hsp70 proteins. The DnaK1 protein has a calculated molecular mass of $75 \mathrm{kDa}$, and DnaK3 has a calculated molecular mass of $86 \mathrm{kDa}$. All three proteins share the common DnaK domain structure. The C-terminal region does not show a high degree of sequence similarity, but the C-terminal domains of Hsp70 proteins are in general not highly conserved. Based on the sequence analysis, all three
Synechocystis DnaK proteins could fulfil similar physiological functions but it is not yet clear if all proteins are functionally expressed in Synechocystis and if the functions overlap in vivo.

\section{Expression and localization of three DnaK proteins in Synechocystis}

Expression of the three different DnaK isoforms was tested by Western blot analysis using antibodies specifically recognizing the individual proteins. Since the three DnaK proteins encoded in Synechocystis share a high degree of sequence similarity (Fig. 1) it was likely that an antibody raised against one protein also recognizes the other isoforms. Therefore, antibodies were raised against peptide stretches that are specific for one protein (underlined in Fig. 1). To test whether the generated antibodies recognized the individual DnaK proteins and are specific for one 


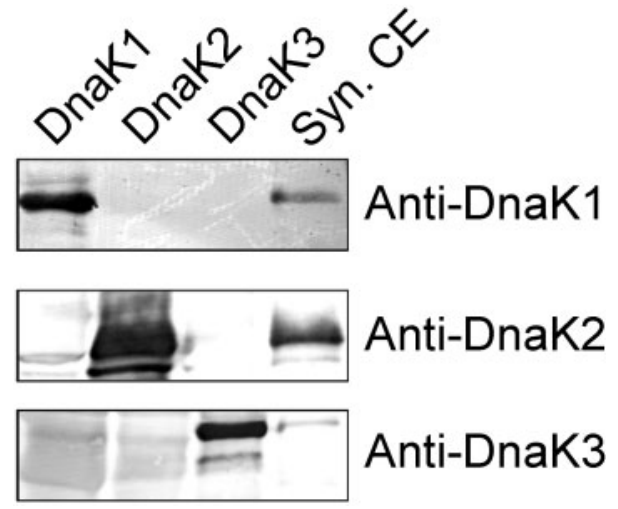

Fig. 2. All three DnaK proteins are expressed in vivo in Synechocystis. The three DnaK proteins were heterologously expressed in E. coli $\Delta d n a K 52$. Equal protein amounts of cellular extract together with total extract of Synechocystis wild-type cells were subjected to Western blot analysis. The individual DnaK proteins were detected using the corresponding peptide antibody. Syn. CE, Synechocystis cellular extract.

isoform, we heterologously expressed the three Synechocystis proteins in E. coli for further analyses. As can be seen in Fig. 2, all antibodies recognized the corresponding DnaK proteins, which were heterologously expressed in E. coli, and all antibodies specifically detected only a single DnaK protein. Since the antibodies showed a high degree of specificity and allowed detection of the individual DnaK proteins they were used to test the expression of the three DnaK proteins in Synechocystis cells. After separation of Synechocystis whole-cell extract by SDSPAGE, all three DnaK isoforms were detected by Western blot analysis (Fig. 2). This observation proves that all three
dnaK genes are functionally expressed in Synechocystis and suggested a specific physiological function for each protein.

To further determine the subcellular localization of the individual DnaK proteins, soluble proteins of Synechocystis wild-type cells were separated from membranes and the individual fractions were subjected to Western blot analysis (Fig. 3). While DnaK1 and DnaK2 were mainly detected in the soluble protein fraction, DnaK3 was almost exclusively found attached to Synechocystis membranes. Since for none of the three DnaK proteins has a signal anchor been predicted by computational methods we further investigated membrane attachment of the DnaK proteins by alkali extraction using carbonate as well as $\mathrm{NaOH}$. As can be seen in Fig. 3, while the DnaK proteins can be totally extracted from membranes with $\mathrm{NaOH}$, they remain almost completely in the pellet upon extraction with $\mathrm{Na}_{2} \mathrm{CO}_{3}$. These results suggest that all three DnaK proteins strongly bind to membranes although they lack any membranespanning domains.

\section{Deletion of the dnaK genes}

The observation that all three DnaK proteins are expressed in Synechocystis raised the questions if all three proteins are essential for viability, if the functions of the three proteins overlap and can be taken over by another protein, or if each DnaK protein fulfils a specialized function in vivo. To study if the individual proteins have specific or overlapping physiological functions, we attempted to delete the three genes individually in Synechocystis (Fig. 4a). A kanamycin resistance cassette was introduced into each $d n a K$ gene on a plasmid and the deletion constructs were transformed into Synechocystis, which is naturally competent and integrates DNA into the chromosome via homologous recombination

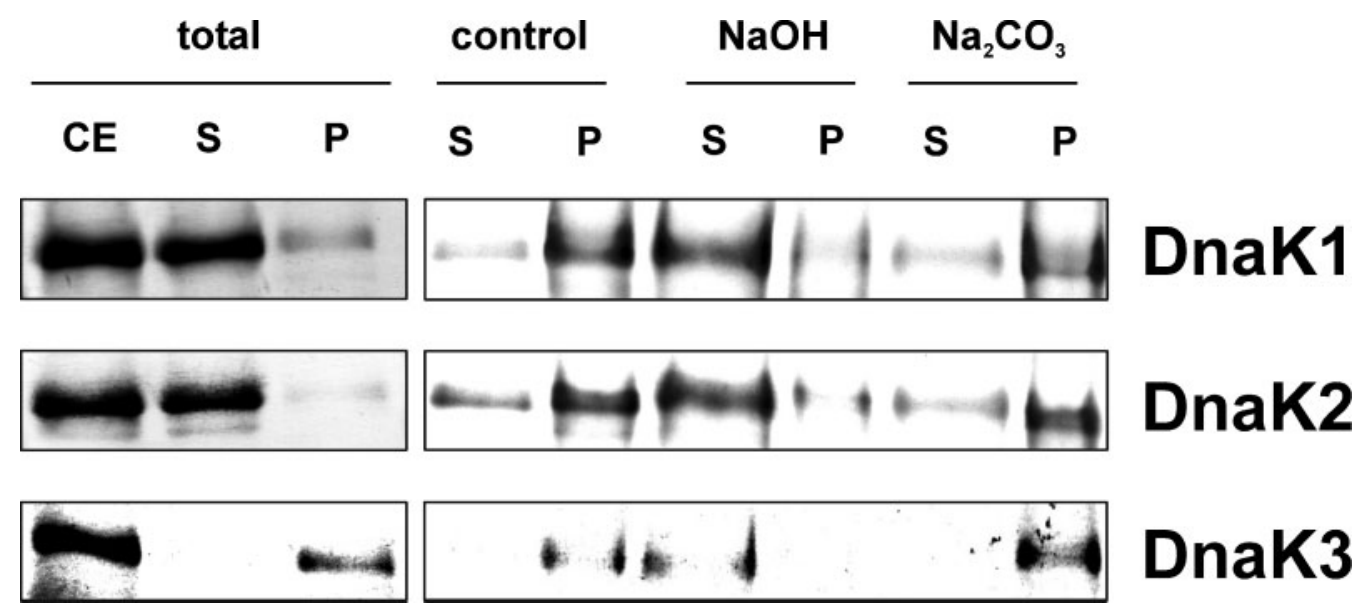

Fig. 3. Cellular localization of the DnaK proteins from Synechocystis. Total cellular extract (CE) of Synechocystis wild-type cells was separated into soluble $(S)$ and membrane protein $(P)$ fractions. Membranes of a Synechocystis wild-type culture were incubated with buffer containing either $100 \mathrm{mM} \mathrm{NaOH}$ or $100 \mathrm{mM} \mathrm{Na}_{2} \mathrm{CO}_{3}$. Non-extracted proteins in the membrane pellet fraction $(P)$ were separated from extracted proteins in the soluble fraction $(S)$. Equal volumes of the corresponding fractions were used for Western analysis. 


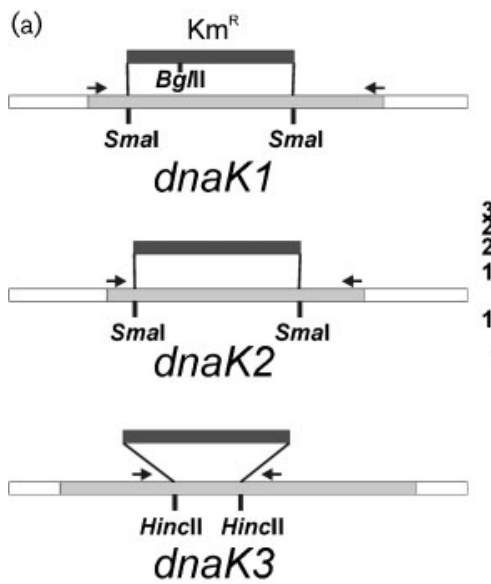

(b)

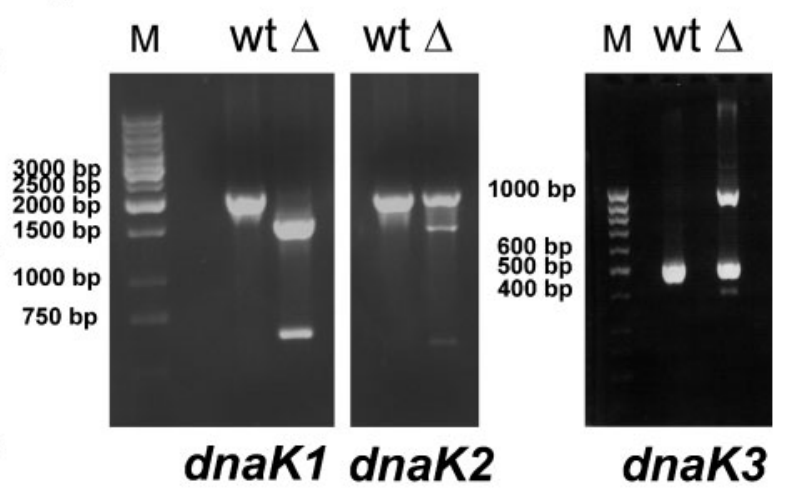

(c)
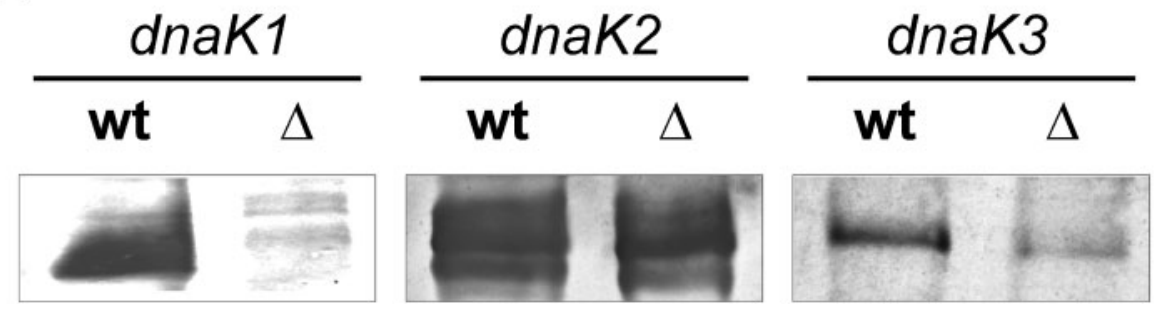

Fig. 4. The $d n a K 2$ and $d n a K 3$ genes are essential for viability of Synechocystis. (a) The individual dnaK genes of Synechocystis were disrupted by insertion of a kanamycin resistance cassette as shown. (b) Analysis of the genomic DNA from the resulting mutant strains revealed that only the dnaK1 gene can be deleted completely. Genomic DNA of the dnaK mutant strains was analysed by PCR and restriction digested with Bg/ll. For the dnaK1 disruption, restriction resulted in fragments of $1500 \mathrm{bp}$ and $600 \mathrm{bp}$, representing a direct orientation of the kanamycin resistance cassette present in every genomic copy of dnaK1. In the case of the dnaK2 mutant, a major amount of the wild-type gene (2000 bp) was still present in addition to disrupted genomic copies. Amplification of the dnaK3 genomic region resulted in a fragment of 600 bp representing the wildtype gene and a fragment of $1400 \mathrm{bp}$ corresponding to the inserted resistance marker, which led to fragments of $1000 \mathrm{bp}$ and $400 \mathrm{bp}$ after restriction with $\mathrm{Bg} / \mathrm{ll}$, indicating a direct orientation of the inserted resistance cassette. M, molecular size markers. (c) Downregulation of DnaK protein amounts in the Synechocystis $\Delta d n a K$ mutants. Synechocystis wild-type and $\Delta d n a K$ mutant strains were harvested in the exponential growth phase. Equal protein amounts of total cellular extracts were analysed by Western blotting.

(Williams, 1988). Synechocystis contains multiple genome copies, and to test if all copies of the dnaK genes were disrupted, we isolated genomic DNA of the mutant strains and performed analytical PCR and restriction analysis to examine the $d n a K$ genomic regions (Fig. 4b). In the $\Delta d n a K 1$ strain the dnaK1 gene was completely deleted and, therefore, dnaK1 is not essential for the viability of Synechocystis cells. In contrast to the dnaK1 deletion strain, we still observed wild-type $d n a K 2$ genomic copies in the $\Delta d n a K 2$ strain. This confirms that this gene cannot be completely deleted and thus fulfils an essential function under the tested growth conditions. Also in the case of the $d n a K 3$ gene we still detected the wild-type dnaK3 fragment in the mutant strain, indicating that the gene cannot be completely replaced and is therefore essential for cell viability, as $d n a K 2$ is. Furthermore, in the strains where some of the wild-type dnaK2 or dnaK3 genes have been disrupted, the amount of expressed DnaK2 proteins remained similar and the amount of DnaK3 was somewhat reduced when compared to the wild-type (Fig. 4c). In contrast, in the $\Delta d n a K 1$ strain we were no longer able to detect the DnaK1 protein, as expected. To test whether the disruption of dnaK1 has any impact on the Synechocystis cells, we characterized the mutant strain in parallel with the wild-type. Interestingly, we were not able to observe any changes of the phenotype with the $\Delta d n a K 1$ strain. Pigment content and growth rates were similar to wild-type cells, as was photosynthetic oxygen production and the relative amounts of photosystem 2 and photosystem 1 (data not shown). These observations suggest that DnaK1 has no essential function under any of the chosen growth conditions. 


\section{Complementation of an E. coli TS $\Delta d n a K$ strain}

To test whether expression of the individual Synechocystis DnaK proteins complements a temperature-sensitive E. coli $\Delta d n a K$ strain, the individual Synechocystis dnaK genes, as well as the E. coli dnaK gene (control), were cloned into a pMal-c2-based expression plasmid. The individual plasmids were transformed into E. coli $\Delta d n a K 756$ and subsequently grown at $30{ }^{\circ} \mathrm{C}$ and $42{ }^{\circ} \mathrm{C}$. As can be seen in Fig. 5(a), only expression of the E. coli DnaK protein restored growth of the temperature-sensitive $E$. coli $\Delta d n a K$ strain at $42{ }^{\circ} \mathrm{C}$, whereas expression of none of the Synechocystis dnaK genes could complement the growth defect of the E. coli cells. Even when the growth temperature and/or the concentration of IPTG used for induction of the DnaK expression were varied, a functional complementation of the temperature-sensitive phenotype was never observed.

To further exclude that a disturbed $d n a K$ expression had caused the missing complementation competence, total cell extract, soluble and membrane-bound proteins, as well as

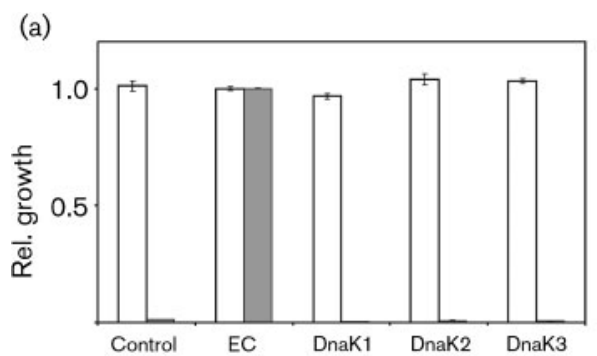

(b)

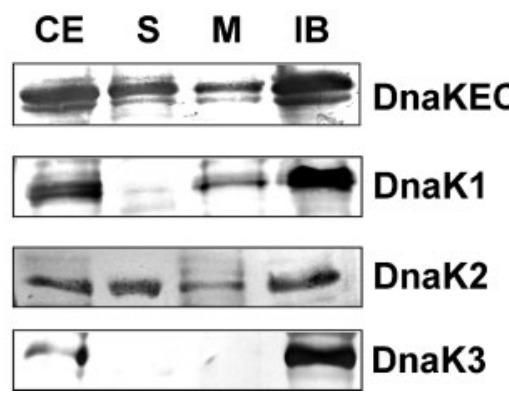

Fig. 5. Complementation of a temperature-sensitive $E$. coli $\Delta d n a K 756$ strain. (a) The individual Synechocystis dnaK genes, as well as $E$. coli $d n a K$, were expressed in $E$. coli $\Delta d n a K 756$ cells and grown at $30{ }^{\circ} \mathrm{C}$ (white bars) and $42{ }^{\circ} \mathrm{C}$ (shaded bars), respectively. $\mathrm{OD}_{600}$ was measured and the $\mathrm{OD}_{600}$ of the control strain, which expresses the E. coli DnaK protein, was set as 1 . Only the expression of the $d n a K$ gene from $E$. coli restored the growth defect. Control: empty expression plasmid. (b) Expression and subcellular localization of the individual Synechocystis dnaK gene products after heterologous expression in E. coli $\Delta d n a K 756$. Total cellular extract (CE) as well as inclusion bodies (IB), soluble proteins (S) and membrane-bound proteins $(M)$ were separated by SDS-PAGE, and the individual DnaK proteins were detected by Western blot analyses. inclusion bodies were prepared and separated by SDSPAGE. As can be seen in Fig. 5(b), all proteins were expressed in the temperature-sensitive E. coli strain but only DnaK2 was mainly expressed into the cytoplasm. DnaK1 as well as DnaK3 were found either deposited in inclusion bodies or attached to the E. coli cytoplasmic membrane. The subcellular localization of DnaK1 and DnaK3 could already explain the missing complementation after expression of these two proteins, as further discussed below.

\section{The DnaK3 C terminus is essential}

Whereas the nucleotide- and substrate-binding domains of the three Synechocystis DnaK proteins are highly homologous (Fig. 1), the proteins have highly diverse $\mathrm{C}$ termini and, furthermore, the $\mathrm{C}$ terminus of DnaK3 is extended, when compared to the two other DnaK proteins. Nimura et al. (1996) proposed that the C terminus of the DnaK3 protein from Synechococcus sp. PCC 7942 can be deleted without altering the phenotype of the generated strain when compared to the wild-type. This observation was unexpected since all cyanobacterial DnaK3 proteins appear to contain a prolonged C terminus, which strongly suggests an essential in vivo function of this domain. To analyse the potential function of the DnaK3 C-terminal extension in Synechocystis we tried to express in Synechocystis a truncated version of DnaK3 which lacks the last 78 amino acids. To this end, the full-length, as well as the truncated $d n a K 3$ gene, were integrated into a neutral site of the Synechocystis genome, and both genes were controlled by the original dnaK3 promoter. After several rounds of selection the additional genes were completely integrated into the Synechocystis genome and we tested if expression of the full-length as well as of the truncated DnaK3 proteins at a different site of the Synechocystis chromosome facilitates complete deletion of the original dnaK3 gene. Therefore, we attempted to completely replace the original $d n a K 3$ gene with the cat gene, which encodes the chloramphenicol acetyltransferase. After several rounds of selection on selective medium the $d n a K 3$ gene was completely replaced in the strain in which the full-length dnaK gene was expressed from a different site on the chromosome (Fig. 6). This observation confirms that deletion of dnaK3 is possible when the gene is expressed from a different locus and that, therefore, the result shown in Fig. 4 was not caused by polar effects of the deletion construct on flanking genes. In contrast, expression of the C-terminally truncated dnaK3 gene from a different site of the Synechocystis chromosome did not result in complete replacement of the original dnaK3 gene. This observation proves that the $\mathrm{C}$ terminus of DnaK3 is absolutely essential under the chosen experimental conditions, and a truncated DnaK3 protein cannot fulfil the physiological functions of DnaK3.

\section{Differential heat-shock response of DnaK proteins}

The expression of DnaK2 from Synechocystis has previously been shown to be upregulated upon heat shock and several 


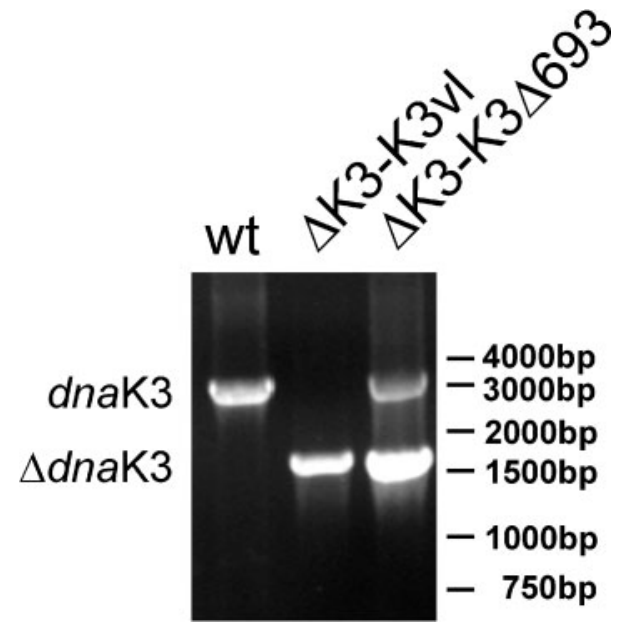

Fig. 6. The DnaK3 C terminus is essential for the specific DnaK3 function in vivo. Genomic DNA from Synechocystis wild-type cells, as well as of cells in which the full-length DnaK3 protein is expressed from a different site of the chromosome ( $\Delta \mathrm{K} 3-\mathrm{K} 3 \mathrm{vl})$, or a truncated version $(\Delta \mathrm{K} 3-\mathrm{K} 3 \Delta 693)$ is expressed, was prepared and used in a subsequent PCR. To test if the original dnaK3 gene could be replaced by a chloramphenicol resistance cassette (cat), primers were used which amplify the original dnaK3 gene region including about $400 \mathrm{bp}$ up- and downstream of the gene. The wild-type fragment was $3100 \mathrm{bp}$ whereas the fragment containing the cat gene instead of $d n a K 3$ was only $1600 \mathrm{bp}$.

other stresses like UV light, ethanol, salt and high light (Chitnis \& Nelson, 1991; Fulda et al., 2006; Mary et al., 2004; Varvasovszki et al., 2003). Therefore, we addressed the question whether the three individual dnaK genes of Synechocystis are induced upon heat shock. To test this on a protein level, Synechocystis wild-type cells were shifted from $34{ }^{\circ} \mathrm{C}$ to $43{ }^{\circ} \mathrm{C}$ and samples were subsequently taken at various time points. Crude cell extracts were separated on SDS-gels and the amount of individual DnaK proteins was examined by Western blot analysis. As can be seen in Fig. 7(a), the protein levels of each DnaK protein irregularly increased and decreased during heat shock. A rapid increase of the protein amounts within the first $15 \mathrm{~min}$ after the temperature shift was observed followed by a decrease of the protein levels and a subsequent slow increase. Apparently, the DnaK2 protein level at $420 \mathrm{~min}$ is much higher than the level before heat stress, which also seems to be the case for the DnaK3 protein. To further support the unexpected observation that DnaK expression is not gradually increased after heat shock and to exclude experimental artefacts, we further tested the promoter activities of the three $d n a K$ genes under heat stress to compare changes in the protein level with the promoter activities. The dnaK promoter regions were fused to a bacterial $l u x A B$ reporter gene as described in Methods, and specific Synechocystis reporter strains were generated. An analysis of the promoter activities of the three dnaK reporter strains under photoautotrophic growth conditions demonstrated that the $d n a K 2$ promoter shows the highest activity, followed by the dnaK3 promoter (Fig. 7b). The dnaK1 promoter was found to be not strongly but significantly active, which further supports the apparent detection of DnaK1 by Western analyses (Fig. 7a). The $d n a K$ reporter strains generated were subsequently shifted to higher temperatures and the individual promoter activities were determined at various time points to follow changes in the promoter activities upon heat stress. The activities of the individual $d n a K$ promoters were set as one at time point zero and all changes are shown relative to the activities before heat stress. As can be seen in Fig. 7(c), the activities of all three dnaK promoters showed a rapid increase during the first $15 \mathrm{~min}$ after shifting the cultures to the higher temperature. However, while the promoter activities of dnaK1 and dnaK3 only slightly increased (about twofold), the dnaK2 promoter activity was already significantly higher at this stage and reached its maximum after $30-45 \mathrm{~min}$. In all three cases, the promoter activity levels rapidly declined after the initial fast increase before they slowly increased again. These observations strongly support the data obtained by Western blot analysis. Based on the promoter activity measurements, only the dnaK2 promoter is significantly upregulated upon heat shock and stays above the original level during the entire period at higher temperature. This upregulation can also be observed on the DnaK2 protein level by Western analysis (Fig. 7a). On the protein level also DnaK3 synthesis seemed to be slightly increased during heat shock, which was not observed in the promoter activity measurement, but the amount of DnaK proteins might also be regulated on the translational level or on the level of protein degradation.

\section{DISCUSSION}

\section{On the existence of multiple DnaK proteins in cyanobacteria}

After annotation of the first completely sequenced genome of a cyanobacterium it became evident that several proteins are encoded by gene families in Synechocystis sp. PCC 6803 (Kaneko et al., 1996; Kaneko \& Tabata, 1997). The probably best characterized families are the psbA1-3 and the petC1-3 families in Synechocystis (Mate et al., 1998; Mohamed et al., 1993; Salih \& Jansson, 1997; Schneider et al., 2002, 2004a, b). Obviously, the potential to encode a protein by various genes has proven evolutionarily successful, and it has been speculated that the possibility to regulate an interplay between various genes and proteins could be one way for cyanobacteria to respond to different environments and to environmental changes (Schneider \& Schmidt, 2005). This assumption would imply that the proteins fulfil identical, or at least very similar, functions in vivo, as has been observed for example for members of the PsbA protein family (Mohamed et al., 1993; Salih \& Jansson, 1997). But why do cyanobacteria need three DnaK 
(a)

\section{Time after heat shock (min) \\ $\begin{array}{llllllllllll}0 & 15 & 30 & 45 & 60 & 90 & 120 & 180 & 240 & 300 & 360 & 420\end{array}$

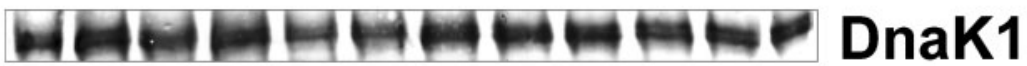

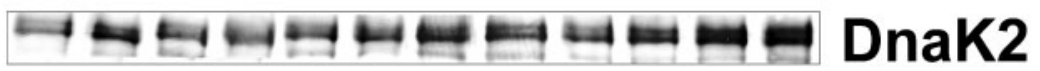

Iin a - - - - - - - DnaK3

(b)

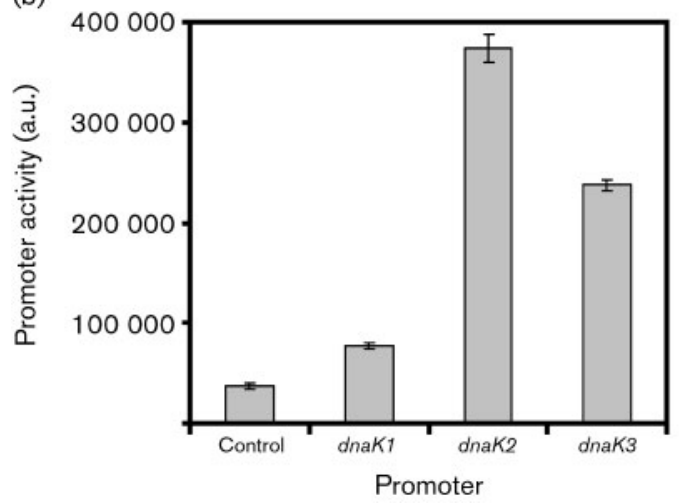

(c)

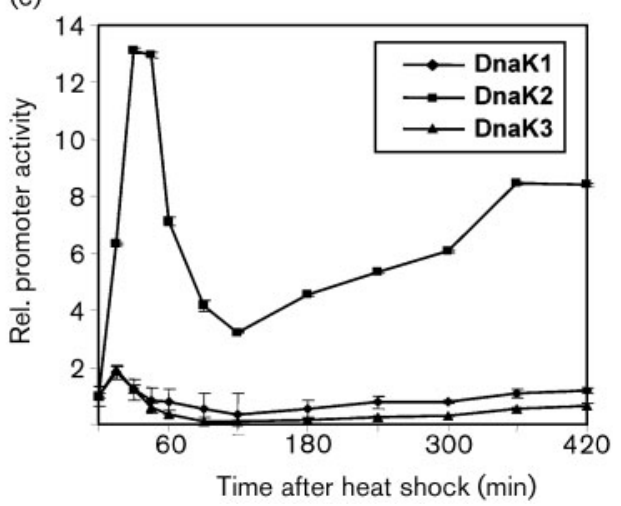

Fig. 7. Heat-shock response of DnaK expression in Synechocystis. (a) Influence of heat stress on DnaK protein levels. An exponentially growing Synechocystis wild-type culture was divided into $100 \mathrm{ml}$ culture samples and shifted from $34{ }^{\circ} \mathrm{C}$ to 43 ${ }^{\circ} \mathrm{C}$. Samples were taken at the indicated time points. Equal protein amounts of total cellular extracts were subjected to Western blot analysis. (b) Relative promoter activities of the three dnaK genes. The promoter regions of the three individual dnaK genes were fused to the bacterial luXAB reporter gene as described in Methods. Promoter activities were measured for $30 \mathrm{~s}$ after addition of $1 \mathrm{mM}$ decanal. As a control a Synechocystis reporter strain was constructed in which no promoter was fused to the reporter gene (background fluorescence). (c) Promoter activity changes of the dnaK genes during heat shock. Cultures (100 $\mathrm{ml}$ ) of the dnaK promoter-probe strains at an $\mathrm{OD}_{750}$ of 0.5 were shifted to $43^{\circ} \mathrm{C}$. Samples were taken for luminescence measurement at the indicated time points. Mean values of three independent measurements were normalized to the background values of the control strain. All activities are shown relative to the activity at time point 0 (before temperature shift), which was set as 1 .

proteins when other bacteria have only one and even this is dispensable?

So far, several cyanobacterial genomes have been completely sequenced and in all these genomes several DnaK proteins are encoded. Based on a computational analysis, these proteins can clearly be clustered in three distinct groups, representing the three individual DnaK proteins (Fig. 8). It is noteworthy that the DnaK2 branch shows the highest sequence homology to other DnaK proteins from bacteria and chloroplasts.

The observation that in all cyanobacteria examined a DnaK protein family exists indicates that the existence of more than one DnaK protein is of physiological importance, especially for these bacteria. As shown in Fig. 1, the amino acid sequences of the three Synechocystis DnaKs are highly conserved and the mainly observed differences are the Cterminal extensions of the protein. However, sequence analysis of these extensions does not allow any conclusions to be drawn about the potential functional differences of the proteins. It is, nevertheless, striking that all DnaK3 proteins have an extra C-terminal extension and in all available DnaK3 sequences a motif rich in tryptophan and aspartic acid can be found at the very C-terminal end of this domain (compare Fig. 1).

\section{Expression and subcellular localization of DnaKs}

One major goal of this study was to answer the question if all three DnaK proteins are functionally expressed in Synechocystis. Based on Western analyses it has been observed that three DnaK proteins are expressed in the cyanobacterium Synechococcus PCC 7942 (Nimura et al., 2001), whereas it has recently been proposed that only DnaK2 is expressed in Synechocystis (Varvasovszki et al., 2003). But since the existence of a DnaK protein family is 


\section{DnaK2}

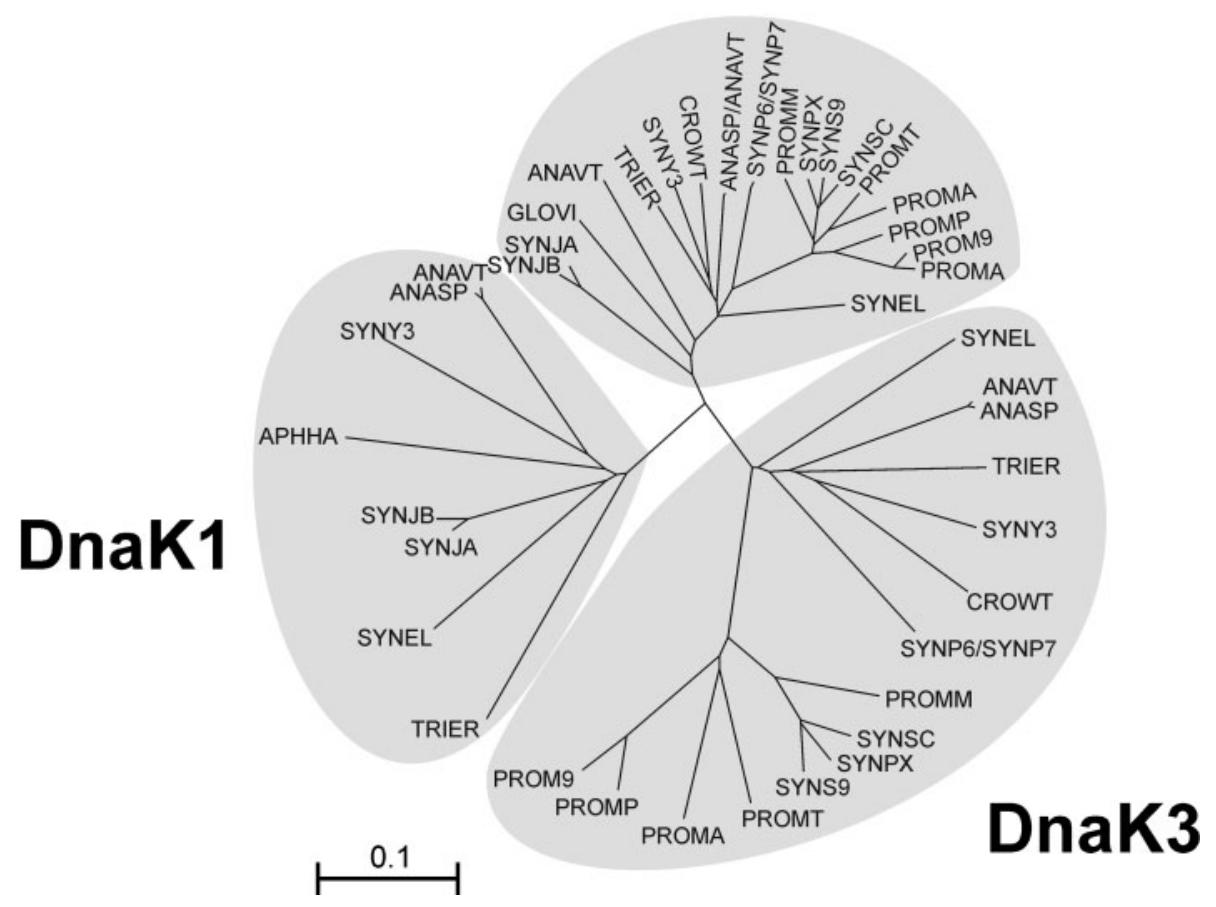

Fig. 8. Phylogenetic tree of selected cyanobacterial DnaK proteins. The tree was calculated using the program CLUSTAL $X$. The three DnaK groups are indicated. The abbreviations used are as follows: ANAVT, Anabaena variabilis (strain ATCC 29413/ PCC 7937); ANASP, Anabaena sp. (strain PCC 7120); APHHA, Aphanothece halophytica; CROWT, Crocosphaera watsonii; SYNP7, Synechococcus sp. (strain PCC 7942) (Anacystis nidulans R2); SYNP6, Synechococcus sp. (strain ATCC 27144/ PCC 6301/SAUG 1402/1) (Anacystis nidulans); SYNEL, Synechococcus elongatus (Thermosynechococcus elongatus); SYNS9, Synechococcus sp. (strain CC9902); SYNSC, Synechococcus sp. (strain CC9605); SYNPX, Synechococcus sp. (strain WH8102); SYNY3, Synechocystis sp. (strain PCC 6803); PROMP, Prochlorococcus marinus subsp. pastoris (strain CCMP 1378/MED4); PROMT, Prochlorococcus marinus (strain NATL2A); PROMM, Prochlorococcus marinus (strain MIT 9313); PROMA, Prochlorococcus marinus; PROM9, Prochlorococcus marinus (strain MIT 9312); PROMA, uncultured Prochlorococcus marinus clone HOTOM-8F9; GLOVI, Gloeobacter violaceus; SYNJA, Synechococcus sp. (strain JA-3-3Ab) (Cyanobacteria bacterium Yellowstone A-Prime); SYNJB, Synechococcus sp. (strain JA-2-3B'a(2-13)) (Cyanobacteria bacterium Yellowstone B-Prime); TRIER, Trichodesmium erythraeum IMS101.

conserved in cyanobacteria it appeared likely that also in Synechocystis all three proteins are expressed and active. To address this question we performed Western blot analysis and we could show that in Synechocystis clearly all three DnaK proteins were recognized by the specific antibodies (Fig. 2), which is in agreement with the situation in Synechococcus (Nimura et al., 2001). It was, however, possible that the discrepancy between this study and that of Varvasovszki et al. (2003) was based on different growth conditions, which may have resulted in different expression of the three $d n a K$ genes. However, besides the expression of DnaK2, which has been detected in several studies, in a recent proteomic shotgun approach also DnaK3 has been detected (Gan et al., 2005), and also the DnaK1 protein has been found in a proteomic study of salt stress response in Synechocystis (Fulda et al., 2006). Regardless of the growth conditions we were able to detect the expression of all three DnaK proteins in Synechocystis, and at this stage we cannot explain the different observations made here and by Varvasovszki et al. (2003). Based on our results we conclude that three DnaK proteins are constitutively expressed in Synechocystis, and, under normal growth conditions, the dnaK2 promoter has the highest activity followed by the dnaK3 and dnaK1 promoters (Fig. 7b). When compared to the other two, the dnaK1 promoter has a weak but significant activity and the DnaK1 protein was also clearly detected in Western blot analyses (Fig. 2).

Analysis of the subcellular localization of the DnaK proteins showed that while DnaK1 and DnaK2 can mainly be found in Synechocystis soluble cell extract, DnaK3 was only found attached to Synechocystis membranes and no protein was found in the soluble protein fraction. In Synechococcus DnaK3 is bound to thylakoid membranes, and it was further suggested that the protein is bound via the peptide-binding domain to the membrane (Nimura $e t$ 
al., 1996). This interaction would imply that DnaK3 is bound to another, membrane-integral protein. In general, the affinity of DnaK proteins to bind to substrates is low when the protein is loaded with ATP, whereas the proteins bind tightly to substrates when ADP is bound. To test for the potential involvement of the substrate-binding domain, we incubated membranes in the presence of $10 \mathrm{mM}$ ATP as well as in the presence of apyrase, which hydrolyses ATP. In both cases, we did not observe a significant difference between membrane attached and soluble DnaK3, which suggests that the peptide-binding domain is not critical for membrane attachment (data not shown). After extraction of Synechocystis membranes with $100 \mathrm{mM} \mathrm{Na} \mathrm{CO}_{3} \mathrm{DnaK}_{3}$ was still found attached to membranes, and only after extraction of membranes with $0.1 \mathrm{M} \mathrm{NaOH}$ was the membrane-bound fraction released into the soluble supernatant (Fig. 3). These observations prove that DnaK3 is not transmembrane, although the protein is very tightly attached to the membrane surface.

In contrast to DnaK3, DnaK1 and DnaK2 were mainly found in the soluble protein fraction from Synechocystis and only a minor protein fraction was membrane associated. It was, however, remarkable that also the membrane-associated fractions of DnaK1 and DnaK2 could not be extracted efficiently from membranes by $\mathrm{Na}_{2} \mathrm{CO}_{3}$ extraction (Fig. 3). Therefore, all DnaK proteins appear to be at least partly attached to membranes.

\section{Physiological functions of multiple DnaK proteins}

The observation that a $d n a K$ gene family is common in cyanobacteria indicates that the individual proteins have distinct physiological functions in vivo. In the two cyanobacteria Synechococcus PCC 7942 and Synechocystis PCC 6803 three DnaK proteins are functionally expressed, which further supports this assumption. In line with a proposed important function we were not able to delete the dnaK2 and dnaK3 genes. The two encoded proteins are therefore essential in Synechocystis and have specific, yet not redundant, functions. If the functions of these two proteins overlapped one would have expected that the genes could be deleted individually but not in combination. Since even the deletion of a single gene was not possible, both proteins seem to have a distinct physiological role, which is further supported by the observed differences in the subcellular localization. However, gene disruption was perhaps not possible due to polar effects of the intended deletion on flanking genes. Based on a sequence analysis, dnaK2 is not organized in an operon, whereas $d n a K 3$ is organized in a gene cluster with a dnaJ gene. However, since expression of DnaK3 from a different site of the Synechocystis chromosome allowed complete deletion of the original dnaK3 gene without altering the strain's phenotype (Fig. 6), polar effects of the dnaK3 deletion on adjacent genes can be excluded. Furthermore, the observation that even after replacement of some wildtype dnaK3 genes the DnaK3 protein level was not dramatically altered (Fig. 4) strongly suggests that this protein is crucial. In contrast, after deletion of dnaK1 the mutant's phenotype was indistinguishable from the wildtype. Since DnaK1 is expressed in wild-type cells, it is very likely that it has a physiological function, which either has not been identified yet or can be taken over by any of the two remaining DnaK proteins. But what could be the physiological functions of three DnaK proteins in Synechocystis?

The DnaK2 protein from Synechococcus PCC 7942 functionally complemented a temperature-sensitive $\Delta d n a K E$. coli strain, whereas the two other Synechococcus DnaK proteins could not (Nimura et al., 2001). All attempts to complement a temperature-sensitive E. coli $\Delta d n a K$ strain with the DnaK proteins from Synechocystis failed and even the DnaK2 protein from Synechocystis could not complement the defect. This result should, however, be taken with caution since it does not clearly show that the three proteins do not have DnaK-like functions. In the case of DnaK3 the missing complementation was not surprising since the protein was only found in inclusion bodies after expression in E. coli. Therefore, the protein could most likely not fulfil the function of a cytoplasmic Hsp70. Since DnaK proteins in general work in a concerted mechanism with co-chaperones ( $\mathrm{GrpE}$ and DnaJ), it is also possible that the individual DnaK proteins from either Synechocystis or Synechococcus cannot functionally interact with the cochaperones from E. coli, and it has indeed already been shown that co-expression of a DnaJ protein is needed to complement the E. coli $\Delta d n a K$ defect with proteins from a different organism (Mogk et al., 1999). A co-expression of the Synechocystis DnaK proteins with a DnaJ protein is, however, not straightforward. In the genome of Synechocystis several DnaJ proteins are encoded (Kaneko et al., 1996). It is very likely that the individual functions of the three DnaK proteins are further defined by distinct interactions with individual DnaJ proteins, and a major task of our future work is to describe this functional network. Besides interactions of DnaK proteins with cochaperones it has become evident in recent years that also individual Hsp70 proteins can functionally interact (Steel et al., 2004; Yam et al., 2005). Therefore, differential interactions between individual DnaK proteins from Synechocystis could also determine their physiological functions.

It appears, however, already safe to argue that the DnaK3 C terminus is essential for the physiological function of the protein, since a C-terminally truncated DnaK3 version cannot substitute for the full-length protein in vivo (Fig. 6). Surprisingly, it has been reported that a C-terminally truncated DnaK3 protein from Synechococcus PCC 7942 can substitute for the wild-type protein without affecting the phenotype of the cyanobacterial strain (Nimura et al., 1996). While in this study only the last 78 amino acids of DnaK3 were deleted, in the study of Nimura et al. (1996) the last 150 residues were deleted, and this truncation should affect the physiological function of the protein even more severely. At this stage we cannot explain these 
different observations but the disparity may indicate physiological differences between the in vivo function of DnaK3 in the two cyanobacterial strains.

\section{Different heat-shock responses of the three DnaK proteins}

After transferring Synechocystis cells from $34{ }^{\circ} \mathrm{C}$ to $43{ }^{\circ} \mathrm{C}$ we observed changes in the protein levels for all three DnaK proteins. In Synechococcus it has been described that the steady-state level of DnaK3 did not change after heat shock whereas the protein levels of DnaK1 and DnaK2 did change. The DnaK1 protein level decreased after $120 \mathrm{~min}$ of heat stress whereas the DnaK2 level was slightly increased (Nimura et al., 2001). As can be seen in Fig. 7, we observed an initial decrease of the DnaK1 and DnaK3 protein levels after growing the cells under heat stress, but both protein levels reached the wild-type level again after 420 min. In contrast, we observed a strong DnaK2 overexpression in Synechocystis after heat shock. A stressinduced increase of DnaK2 expression in Synechocystis has been observed on both the RNA and protein level (Choi et al., 2000; Fulda et al., 2006; Huang et al., 2006; Mary et al., 2004; Varvasovszki et al., 2003), but the stress response was only monitored at one time point after stress. Interestingly, after a rapid initial increase the DnaK2 protein level decreased slightly followed by a continuous accumulation of DnaK2. A similar situation was also observed for DnaK1 and DnaK3, although the changes were not as pronounced as in the case of DnaK2. To exclude experimental artefacts we further constructed Synechocystis reporter strains, in which the promoters of the individual $d n a K$ genes control the expression of the reporter. When these strains were used to follow promoter activities of the three dnaK genes we found a similar pattern as observed by Western analysis (Fig. 7c). All three dnaK genes showed an increased promoter activity followed by an activity decrease. The $d n a K 1$ and $d n a K 3$ genes thereafter slowly reached the same expression level as before heat stress; these observations support the data obtained on the protein expression level. After the initial strong increase in the $d n a K 2$ promoter activity also the activity of this promoter markedly decreased, although it still remained above the initial level. The dnaK2 promoter activity then increased gradually, as observed on the protein level. Recently, the heat-stress response of various genes has been followed in Synechocystis and expression of the dnaK2 gene has been tested on the mRNA level 20 and $60 \mathrm{~min}$ after heat stress (Suzuki et al., 2006). In this study accumulation of dnaK2 mRNA was more than 20 -fold increased after 20 min but was only twofold increased after $60 \mathrm{~min}$, when compared to the mRNA level prior to heat stress, and this is in excellent agreement with the finding of this study.

The observation that the promoter activities of all three $d n a K$ genes, and especially of $d n a K 2$, strongly increase directly after heat shock but thereafter markedly decrease is surprising and can most likely not be explained directly by the function of the DnaK proteins. Besides the DnaK protein and the associated co-chaperones, $\sigma^{32}$ factors have important roles in heat-stress response in bacteria (for a recent review see Hengge-Aronis, 2002). E. coli DnaK functionally interacts with the $\sigma^{32}$ factor and is involved in the regulation of its translation as well as in regulation of $\sigma^{32}$ proteolysis. It is possible that the initial strong heatshock response of the $d n a K 2$ gene (Fig. 7) somehow negatively regulates the activity of the $\sigma^{32}$ factor, resulting in downregulation of dnaK expression. But such an assumption has to be made with caution in the absence of any experimental evidence, and we are currently investigating the regulation of $d n a K 2$ expression in more detail.

In general, the observation that a stress response can strongly vary at various time points suggests that studies which determine stress responses at only one time point after induction have to be interpreted with caution. The observed DnaK2 heat stress response was highly dependent on the selected time point after heat stress. The response of the expression of a protein to any external stimuli should always be followed over a period of time to exclude the possibility that a transient activity minimum or maximum is measured.

\section{ACKNOWLEDGEMENTS}

We thank B. Bukau and M. Mayer for providing the E. coli $\Delta d n a k$ strains used in this study, and M. Schroda for stimulating discussions. The excellent technical assistance of C. Escher is gratefully acknowledged.

\section{REFERENCES}

Alexeyev, M. F. (1995). Three kanamycin resistance gene cassettes with different polylinkers Biotechniques 18, 52-56.

Bukau, B. \& Horwich, A. L. (1998). The Hsp70 and Hsp60 chaperone machines Cell 92, 351-366.

Bukau, B. \& Walker, G. C. (1989a). Cellular defects caused by deletion of the Escherichia coli dnaK gene indicate roles for heat shock protein in normal metabolism J Bacteriol 171, 2337-2346.

Bukau, B. \& Walker, G. C. (1989b). Delta dnaK52 mutants of Escherichia coli have defects in chromosome segregation and plasmid maintenance at normal growth temperatures J Bacteriol 171, 60306038.

Bukau, B., Weissman, J. \& Horwich, A. (2006). Molecular chaperones and protein quality control Cell 125, 443-451.

Chitnis, P. R. \& Nelson, N. (1991). Molecular cloning of the genes encoding two chaperone proteins of the cyanobacterium Synechocystis sp. PCC 6803 J Biol Chem 266, 58-65.

Choi, J. S., Kim, D. S., Lee, J., Kim, S. J., Kim, S. I., Kim, Y. H., Hong, J., Yoo, J. S., Suh, K. H. \& Park, Y. M. (2000). Proteome analysis of lightinduced proteins in Synechocystis sp. PCC 6803: identification of proteins separated by 2D-PAGE using N-terminal sequencing and MALDI-TOF MS Mol Cells 10, 705-711.

Cupp-Vickery, J. R., Peterson, J. C., Ta, D. T. \& Vickery, L. E. (2004). Crystal structure of the molecular chaperone HscA substrate binding domain complexed with the IscU recognition peptide ELPPVKIHC $J$ Mol Biol 342, 1265-1278. 
Flaherty, K. M., DeLuca-Flaherty, C. \& McKay, D. B. (1990). Threedimensional structure of the ATPase fragment of a $70 \mathrm{~K}$ heat-shock cognate protein Nature 346, 623-628.

Fulda, S., Mikkat, S., Huang, F., Huckauf, J., Marin, K., Norling, B. \& Hagemann, M. (2006). Proteome analysis of salt stress response in the cyanobacterium Synechocystis sp. strain PCC 6803 Proteomics 6, 2733-2745.

Gan, C. S., Reardon, K. F. \& Wright, P. C. (2005). Comparison of protein and peptide prefractionation methods for the shotgun proteomic analysis of Synechocystis sp. PCC 6803 Proteomics 5, 2468-2478.

Georgopoulos, C. P., Lam, B., Lundquist-Heil, A., Rudolph, C. F., Yochem, J. \& Feiss, M. (1979). Identification of the C. coli dnaK (groPC756) gene product Mol Gen Genet 172, 143-149.

Guzman, L. M., Belin, D., Carson, M. J. \& Beckwith, J. (1995). Tight regulation, modulation, and high-level expression by vectors containing the arabinose PBAD promoter $J$ Bacteriol 177, $4121-4130$

Harrison, C. (2003). GrpE, a nucleotide exchange factor for DnaK Cell Stress Chaperones 8, 218-224.

Harrison, C. J., Hayer-Hartl, M., Di Liberto, M., Hartl, F. \& Kuriyan, J. (1997). Crystal structure of the nucleotide exchange factor GrpE bound to the ATPase domain of the molecular chaperone DnaK Science 276, 431-435.

Hengge-Aronis, R. (2002). Signal transduction and regulatory mechanisms involved in control of the $\sigma^{\mathrm{S}}$ (RpoS) subunit of RNA polymerase Microbiol Mol Biol Rev 66, 373-395.

Huang, F., Fulda, S., Hagemann, M. \& Norling, B. (2006). Proteomic screening of salt-stress-induced changes in plasma membranes of Synechocystis sp. strain PCC 6803 Proteomics 6, 910-920.

Jiang, J., Prasad, K., Lafer, E. M. \& Sousa, R. (2005). Structural basis of interdomain communication in the Hsc70 chaperone Mol Cell 20, 513-524.

Kaneko, T. \& Tabata, S. (1997). Complete genome structure of the unicellular cyanobacterium Synechocystis sp. PCC6803 Plant Cell Physiol 38, 1171-1176.

Kaneko, T., Sato, S., Kotani, H., Tanaka, A., Asamizu, E., Nakamura, Y., Miyajima, N., Hirosawa, M., Sugiura, M. \& other authors (1996). Sequence analysis of the genome of the unicellular cyanobacterium Synechocystis sp. strain PCC6803. II. Sequence determination of the entire genome and assignment of potential protein-coding regions DNA Res 3, 109-136.

Kunert, A., Hagemann, M. \& Erdmann, N. (2000). Construction of promoter probe vectors for Synechocystis sp. PCC 6803 using the light-emitting reporter systems Gfp and LuxAB J Microbiol Methods 41, 185-194.

Lelivelt, M. J. \& Kawula, T. H. (1995). Hsc66, an Hsp70 homolog in Escherichia coli, is induced by cold shock but not by heat shock $J$ Bacteriol 177, 4900-4907.

Liberek, K., Marszalek, J., Ang, D., Georgopoulos, C. \& Zylicz, M. (1991). Escherichia coli DnaJ and GrpE heat shock proteins jointly stimulate ATPase activity of DnaK Proc Natl Acad Sci U S A 88, 2874-2878.

Mary, I., Tu, C. J., Grossman, A. \& Vaulot, D. (2004). Effects of high light on transcripts of stress-associated genes for the cyanobacteria Synechocystis sp. PCC 6803 and Prochlorococcus MED4 and MIT9313 Microbiology 150, 1271-1281.

Mate, Z., Sass, L., Szekeres, M., Vass, I. \& Nagy, F. (1998). UV-Binduced differential transcription of $p s b A$ genes encoding the D1 protein of photosystem II in the cyanobacterium Synechocystis $6803 \mathrm{~J}$ Biol Chem 273, 17439-17444.
Mogk, A., Bukau, B., Lutz, R. \& Schumann, W. (1999). Construction and analysis of hybrid Escherichia coli-Bacillus subtilis dnaK genes $J$ Bacteriol 181, 1971-1974.

Mohamed, A., Eriksson, J., Osiewacz, H. D. \& Jansson, C. (1993). Differential expression of the $p s b A$ genes in the cyanobacterium Synechocystis $6803 \mathrm{Mol}$ Gen Genet 238, 161-168.

Nimura, K., Yoshikawa, H. \& Takahashi, H. (1994a). Sequence analysis of the third dnaK homolog gene in Synechococcus sp. PCC7942 Biochem Biophys Res Commun 205, 2016-2017.

Nimura, K., Yoshikawa, H. \& Takahashi, H. (1994b). Identification of dnaK multigene family in Synechococcus sp. PCC7942 Biochem Biophys Res Commun 201, 466-471.

Nimura, K., Yoshikawa, H. \& Takahashi, H. (1996). DnaK3, one of the three DnaK proteins of cyanobacterium Synechococcus sp. PCC7942, is quantitatively detected in the thylakoid membrane Biochem Biophys Res Commun 229, 334-340.

Nimura, K., Takahashi, H. \& Yoshikawa, H. (2001). Characterization of the dnaK multigene family in the cyanobacterium Synechococcus sp. strain PCC7942 J Bacteriol 183, 1320-1328.

Paek, K. H. \& Walker, G. C. (1987). Escherichia coli dnaK null mutants are inviable at high temperature J Bacteriol 169, 283-290.

Rippka, R., Deruelles, J., Waterbury, J. B., Herdman, M. \& Stanier, R. Y. (1979). Generic assignments, strain histories and properties of pure cultures of cyanobacteria J Gen Microbiol 111, 1-61.

Rospert, S. \& Chacinska, A. (2006). Distinct yet linked: chaperone networks in the eukaryotic cytosol Genome Biol 7, 208.

Salih, G. F. \& Jansson, C. (1997). Activation of the silent $p s b A 1$ gene in the cyanobacterium Synechocystis sp. strain 6803 produces a novel and functional D1 protein Plant Cell 9, 869-878.

Sambrook, J., Fritsch, E. F. \& Maniatis, T. (1989). Molecular Cloning: a Laboratory Manual, 2nd edn. Cold Spring Harbor, USA: Cold Spring Harbor Press.

Schneider, D. \& Schmidt, C. L. (2005). Multiple Rieske proteins in prokaryotes: where and why? Biochim Biophys Acta 1710, 1-12.

Schneider, D., Skrzypczak, S., Anemuller, S., Schmidt, C. L., Seidler, A. \& Rögner, M. (2002). Heterogeneous Rieske proteins in the cytochrome b6f complex of Synechocystis PCC6803? J Biol Chem 277, 10949-10954.

Schneider, D., Berry, S., Volkmer, T., Seidler, A. \& Rögner, M. (2004a). PetC1 is the major Rieske iron-sulfur protein in the cytochrome b6f complex of Synechocystis sp. PCC $6803 \mathrm{~J}$ Biol Chem 279, 39383-39388.

Schneider, D., Volkmer, T., Berry, S., Seidler, A. \& Rögner, M. (2004b). Characterization of the petC gene family in the cyanobacterium Synechocystis PCC 6803 Cell Mol Biol Lett 9, 51-55.

Schoepfer, R. (1993). The pRSET family of T7 promoter expression vectors for Escherichia coli Gene 124, 83-85.

Seaton, B. L. \& Vickery, L. E. (1994). A gene encoding a DnaK/hsp70 homolog in Escherichia coli Proc Natl Acad Sci U S A 91, 2066-2070.

Steel, G. J., Fullerton, D. M., Tyson, J. R. \& Stirling, C. J. (2004). Coordinated activation of Hsp70 chaperones Science 303, 98-101.

Suzuki, I., Simon, W. J. \& Slabas, A. R. (2006). The heat shock response of Synechocystis sp. PCC 6803 analysed by transcriptomics and proteomics J Exp Bot 57, 1573-1578.

Thompson, J. D., Gibson, T., Plewniak, F., Jeanmougin, F. \& Higgins, D. (1997). The CLUSTAL_X Windows interface: flexible strategies for multiple sequence alignment aided by quality analysis tools Nucleic Acids Res 25, 4876-4882.

Varvasovszki, V., Glatz, A., Shigapova, N., Josvay, K., Vigh, L. \& Horvath, I. (2003). Only one dnaK homolog, dnaK2, is active 
transcriptionally and is essential in Synechocystis Biochem Biophys Res Commun 305, 641-648.

Wang, H., Kurochkin, A. V., Pang, Y., Hu, W., Flynn, G. C. \& Zuiderweg, E. R. (1998). NMR solution structure of the $21 \mathrm{kDa}$ chaperone protein DnaK substrate binding domain: a preview of chaperone-protein interaction Biochemistry 37, 7929-7940.

Williams, J. G. K. (1988). Mutations in PSII reaction center Methods Enzymol 167, 766-778.

Yam, A. Y.-W., Albanese, V., Lin, H.-T. J. \& Frydman, J. (2005). Hsp110 cooperates with different cytosolic HSP70 systems in a pathway for de novo folding. J Biol Chem 280, 41252-41261.
Yoshimune, K., Yoshimura, T. \& Esaki, N. (1998). Hsc62, a new DnaK homologue of Escherichia coli Biochem Biophys Res Commun 250, 115-118.

Zhang, Y. \& Zuiderweg, E. R. (2004). The 70-kDa heat shock protein chaperone nucleotide-binding domain in solution unveiled as a molecular machine that can reorient its functional subdomains Proc Natl Acad Sci U S A 101, 10272-10277.

Zhu, X., Zhao, X., Burkholder, W. F., Gragerov, A., Ogata, C. M., Gottesman, M. E. \& Hendrickson, W. A. (1996). Structural analysis of substrate binding by the molecular chaperone DnaK Science 272, 1606-1614.

Edited by: K. Forchhammer 